\title{
Characterization and Classification of Soils and Water in Major Irrigated Lands of Lake Abaya Chamo Basin.
}

Gezimu Gelu ( $\sim$ gezimugelu64@gmail.com )

Arbaminch Agricultural Research Center: Arba Minch Agricultural Research Center alemnesh gelu gezimu ayza

Arbaminch Agricultural Research Center: Arba Minch Agricultural Research Center Chanako dane

Arbaminch Agricultural Research Center: Arba Minch Agricultural Research Center

\section{Research Article}

Keywords: Sodium, Residual Sodium carbonate, Hazard, Electrical conductivity

Posted Date: December 10th, 2021

DOI: https://doi.org/10.21203/rs.3.rs-1055787/v1

License: (c) (i) This work is licensed under a Creative Commons Attribution 4.0 International License.

Read Full License 
1 Characterization and Classification of Soils and Water in Major Irrigated Lands of Lake

2 Abaya Chamo basin

3

4 Abstract

5 Large amount of irrigated land under Lake Abaya Chamo basin is becoming unproductive every year because of salinity and sodicity expansion; consequently farmers are leaving their land out of cultivation due to burning of crops. For sustainable land use and Agricultural water management, it is a very important to examine the chemical composition of soils water and status of their quality. Therefore, the study was aimed to evaluate the physico-chemical properties of soils and irrigation water of irrigated lands under Lake Abaya Chamo basin, located in South East rift valley of Ethiopia. The pH of the soil in the study area ranged from (7.24 to 9.04, 7.54 to 7.91), Electrical conductivity (0.388 to 19.22, 0.644 to 23.6) under Lake Abaya and Chamo, respectively. The results of irrigation water quality showed that the water class of lake Abaya Chamo basin is under harzard status of salinity and sodicity and cannot be recommended for irrigation use. There is a potential danger of sodicity and salinity development in the intended lake basin. Thus, selection of salinity and sodicity resistant crop types, proper irrigation water application methods and other chemical mitigation measures should be designed for sustainability of soil and water productivity. 


\section{INTRODUCTION}

Soil salinity is one of the principal environmental causes of soil degradation and consequently, a source of reduction in biomass. It has been identified as a major process of land degradation and the greatest cause of declining productivity in many irrigated lands (Akram et al., 2013). Globally, about one third of agricultural lands are becoming saline and extend to more than one hundred countries of different climates (Akram et al. ,2010). As available water supplies decrease the reuse of saline drainage and the conjunctive use of fresh and marginal waters will become increasingly common in Ethiopia in near future. This leads to much reduced water availability and increased salinity at the tail end of the river systems, critically impacting these areas. As such determining spatial and temporal trends in water quantity and quality is critical and the development of a framework for the monitoring and management of water quality, especially salt, at a basin scale is required.

According to recent studies (National Taskforce report, 2018), there is uncertainty about the extent, severity and causes of soil salinity and sodicity in irrigated and dry land areas. Sources are not backed up by hard evidence (recent surveys) and are contradictory. These points underscore the need for a comprehensive assessment of the spatial distribution of soil salinity. Particularly there is a need to establish a better picture of the most affected or vulnerable areas and to promote practices that can be used to adapt agricultural production in areas susceptible to climate change. This will contribute to food security and reduce stress on ecosystems (Hodri, and P. Thomas 2011). Soil salinity in agricultural fields is increasing worldwide, mainly due to poor farm management practices and the increasing demand for intensification of agriculture for the short-term benefits of increased food production. This intensification ignores the long-term consequences on 'other services' provided by the soil. It is, therefore, very important to understand the salinity hazard, both spatially and temporally at the regional and national farm levels (Mohammad et. al, 2018).

The main sources and causes of salinity and sodicity are shallow ground water tables and evaporation of moisture from the surface or shallow depths within the profile, natural saline seeps, and use of saline or sodic irrigation waters, inefficient irrigation practices, and poor 
drainage. Despite the wide spread occurrence of salt affected soils in the target districts, we still do not have an accurate cadaster on water quality, salinity extent and severity distribution and exact geographical location as well as their sources, causes, properties and management practices.

Therefore, the main objective of the present investigation was to investigate chemical and physical properties of soil and water in the basin for the characterization of water and soil quality. Analysing of parameters like $\left(\mathrm{P}^{\mathrm{H}}\right.$, electrical conductivity (EC), Sodium absorption ratio (SAR), residual sodium carbonate and others was carried out. Based on the chemical and physical parameters of soil and water the classification of irrigation water and soil was carried out as saline, saline sodic and normal. These research findings will be served as the inlet for the proper management and impact analysis of salt affected soils on crop productivity and soil resources sustainability. Moreover, it will support for modelling of salinity or sodicity impact and crop relative yield performance.

\section{METHODS AND MATERIALS}

\subsection{Description of the study area}

The study was conducted in two districts of recent Gamo Zone namely, Arba Minch Zuria and Mirab Abaya. These districts are the under the Lake Abaya and Chamo basin. Lake Chamo and Abaya are two closely located lakes and only separated by small land surface as shown in Figure 1.

\section{Site selection, soil and water sampling and laboratory analysis}

\subsubsection{Soil sampling and laboratory analysis}

Prior to the opening of soil profiles, personal field observation of the area within the basin was carried out to determine which specific areas should be selected as representative sites of the study area on the basis of land use, history of irrigation, vegetation covers and irrigation water application. The soil samples were collected from village of Wajifo, Yayke Alge , Fura and Omo lante of Mirab Abaya district under Abaya lake basin. Shele Mella and Eligo villages were selected for water and soil sample collection under Chamo lake basin and Sille river. These villages were selected as high spot areas under basin. The soil samples were collected by using purposive sampling procedures to represent soil of the study area. Soil sample was collected from two Profiles (0 to $30 \mathrm{~cm}$ and 30 to $60 \mathrm{~cm}$ ). Soil samples from both 
profile was taken using Auger. From each sampling site soil samples were taken from two profiles; profile 1 and profile 2 . The soil profiles opened on each high spot were described for their morphological properties in the field and soil samples were collected depth wise from each profile for classification of their chemical and physical properties in laboratory.

The collected soil samples was air-dried, ground and sieved through a $2 \mathrm{~mm}$ size sieve and through a $0.5 \mathrm{~mm}$ size sieve for parameter requiring. Particle size distribution was determined by Bouyoucos hydrometer method (Mulat et al, 2028). Soil $\mathrm{pH}$ value was measured by $\mathrm{pH}$ meter in ratio of soil to liquid $(1: 2.5)$. Electrical conductivity measurement was carried out using saturated paste extracts method. Other parameters were analysed procedures outlined by FAO (2002).

\subsubsection{Water sampling and Laboratory analysis}

A water sample was prepared from one representative point of each spot of the basin. The irrigation water samples from the lakes and irrigation scheme was collected in one season. Three samples of water was taken from three representative spots (one from lake Abaya, one from Chamo and one from Sille river) for the analysis of $\mathrm{p}^{\mathrm{H}}, \mathrm{EC}, \mathrm{Ca}^{+2}, \mathrm{Mg}^{+2} \cdot \mathrm{Na}^{+1}, \mathrm{RSC}$, $\mathrm{HCO}^{-}, \mathrm{CO}^{2-}$ and $\mathrm{Cl}^{-1}$

Sodium adsorption ratio (SAR) of the soil solution was calculated from the concentrations of soluble $\mathrm{Na}, \mathrm{Ca}$ and $\mathrm{Mg}$ as follow:

$$
\mathrm{SAR}=\frac{\mathrm{Na}^{+}}{\frac{\sqrt{\mathrm{ca}+2+\mathrm{mg}+2}}{2}}
$$

Residual sodium carbonate (RSC) was calculated using the following formula:

$$
\mathrm{RSC}=\left[\mathrm{HCO}^{-}+\mathrm{CO}^{2-}\right]-\left[\mathrm{Ca}^{2+}+\mathrm{Mg}^{2+}\right] \text {. }
$$

Where concentrations of all constituents were in meq/l for equation 1 and 2.

\subsection{Salinity and Sodicity classes and Residual sodium carbonates (RSC)}

The salinity and sodicity classes of irrigation water were interpreted on basis of USSL Staff 1954 manual. The Salinity classes were interpreted on basis of table 1, Sodicity classes on basis of table 2 and Residual sodium carbonate (RSC) on basis of table 3 .

\subsection{Data analysis}


The data generated from laboratory was analysed by using descriptive statistics. All the data of water and soil samples were edited, coded and analysed using statistical package for social science (SPSS) software version 22.0.

\section{RESULTS AND DISCUSSIONS}

\subsection{Textural classes of soils in the study sites}

To characterizing the physicochemical properties of soils, the sampling site selection was performed on the premise of slope, cultivation year, and vegetation cover and irrigation water application system. Accordingly, for the target districts soil profiles which are representing the target study areas were selected and samples collected. Table 4 represents textural classes' soils across different horizon in numerous spot of target areas.

The ends up in Table 4 and Table 5 show that just in case of Lake Abaya the clay content of most Pedon decreased with depth except some pedos of wajifo, Yayke and Algae sampling spots. Just in case of Lake Chamo the clay content of most Pedon decreased with depth except Eligo spot. The silt content across the layers wasn't consistent just in case both Lake Abaya and Chamo. During this study, very cheap sand content $(5.2 \%)$ recorded within the subsurface layers (30 to $60 \mathrm{~cm}$ depth) of pedon 1 of Omo land 0 to $30 \mathrm{~cm}$ depth of Fura under Lake Abaya. The highest (55.2\%) mean sand contents was recorded at surface layer (0 to $30 \mathrm{~cm}$ depth) of Yayke. Just in case of Lake Chamo rock bottom sand content (1.2\%) was recorded in profile 2 of Eligo. The lower content of sand at the subsurface layers which can show the eluviation of clay and silt from the covering profile layers and accumulation within the below surface of layers and this result in line with the finding of (Mulat et al, 2018). The many variations in respective particle size distribution observed within the different soil layers indicate the presence of distinct lithological discontinuity within the profile (Mulat et al, 2018).

Overall, results of the particle size analysis of this study shows that the bulk of the soils are heavily (clay) textured. These heavily properties of the soil may have an effect on movement of air and water within the soil (Brady and Weil, 2002). Such abrupt changes within the distributions of the sand and silt fractions with corresponding changes within the clay contents with profile depths indicate the occurrence of abrasion and sedimentation processes, leading to deposition of sediments differing in particles sizes and/or parent materials within the area. Similar findings were reported by Mulat et al. (2018) in connection to his study of 
the soils of Raya Valley, Ethiopia. Moreover, Heluf (1985) observed evidences for the presence of litho-logical discontinuities or variability in mineralogy indicating a difference from which the horizons are formed.

\subsection{Chemical properties of soil in the study sites}

\subsubsection{Soil $\mathbf{P}^{\mathrm{H}}$, RSC and Electric conductivity}

The $\mathrm{p}^{\mathrm{H}}$ values of surface soil horizons of the studied pedons varied from 7.24 to 9.02, which can be described as slightly saline and moderately as suggested by Park et al. (2011) in the spots of Lake Abaya (Table 6). As the mean values of parameters show (Table 7), the $\mathrm{p}^{\mathrm{H}}$ values ranged from 7.54 (in Shelle mella at 0 to $30 \mathrm{~cm}$ ) to 7.91 (in Eligo at 30 to $6 \mathrm{ocm}$ ). Generally there is variability of $\mathrm{P}^{\mathrm{H}}$ values in irrigated soils of both lakes. The rise in $\mathrm{pH}$ was attributed to the highest concentration of $\mathrm{HCO}^{-}$and the subsequent results of Residual Sodium Carbonate and in line with the findings of Seid and Genanew (2013).

Electric conductivity of soils in the study sites (Lake Abaya) ranges from non-saline $(0.388$ $\mathrm{ds} / \mathrm{m}$ at depth of 0 to $30 \mathrm{~cm}$ in Algea- 1 to moderately saline $(19.22 \mathrm{ds} / \mathrm{m})$ in Algea-2 at depth of 0 to $3 \mathrm{ocm}$ (Table 6). EC of the second site (Lake Chamo) also ranges from non-saline to moderate saline $(0.644 \mathrm{ds} / \mathrm{m}$ (on the surface soil to 0 to 31$)$ to $(23.6 \mathrm{ds} / \mathrm{m}$ in the surface soils of the lower layers 0 to $30 \mathrm{~cm}$ ) (Table 7).

Indeed, in most of the studied profiles, electrical conductivity (EC) of the soils was higher than $4 \mathrm{ds} / \mathrm{m}$, indicating that there would be actual salinity hazard in the soils of the study area (USA Soli salinity laboratory staff, 1954).

The level of exchangeable sodium percentage of the profile opened at the most low-lying portion of the farm varied from 6.92 at depth of 30 to 30 to 86.09 at depth of 30 to $60 \mathrm{~cm}$ in sampled sites of Lake Abaya. The level of ESP in spot of Lake Chamo ranged from 35.76 at depth of 0 to $30 \mathrm{~cm}$ to 61.68 at depth of 0 to $30 \mathrm{~cm}$. accordingly; the soils represented by these profiles were characterized by Sodicity hazards in both cases. These ESP values greater than 15 show that there is sodium toxicity problem. This indicates that the soils of most profiles are potentially sodic (especially soils under irrigated areas of Yayke and Wajifo). These results agree with the findings of Horneck et al. (2007) who summarized that soils with >15 ESP have a high sodicity risk due to the effects of $\mathrm{Na}$ on soil structure and toxic to crops. 
185 Irrigation water quality was analyzed for determination of SAR, $\mathrm{p}^{\mathrm{H}}$, EC and other important parameters of the irrigation water. An average SAR value of Lake Abaya was found to be 30.357 (Table 9). Thus, the irrigation water quality in Lake Abaya was classified as hazardous in regards of Sodicity and Salinity, thus the water is unsuitable for irrigation use. With regards to Lake Chamo there Average SAR value is 33.04 and the irrigation water is in class of high salinity and very high sodicity problem, the results indicate that the water is unsuitable for irrigation purpose (Table 8). The result of Sille river showed that the average SAR value is 29.05 (Table 9) and therefore the salinity status is medium and water is suitable (safe) for irrigation purpose.

The $\mathrm{p}^{\mathrm{H}}, \mathrm{EC}$ and SAR values clearly indicated that the irrigation water with salt content classified as hazardous in both Lake Abaya and Chamo. These findings in line with findings of Abejehu (1993) and Alamirew (2000) for the Awash River water at the Matahara Sugar State Far with in the Middle Awash Valley Ethiopia reported by Mulat et al. (2018).

The bicarbonate and carbonate ions were the dominant in the irrigation water of lake Chamo and Abaya and which contributed for formation of hazardous RSC. An increment of RSC has direct contribution on formation of salinity and influencing crop production by increasing osmotic pressure in the root zone.

\section{CONCLUSION AND RECOMMENDATIONS}

Efficient management of soil salinity requires better understanding on the extent and distribution of salts. This work focused on the recognition of the problem, by characterizing the physicochemical properties of the soils and irrigation water for intended irrigation scheme with reference to standard suitability class. The results revealed that most of the soil physical properties showed variability in their total distribution within the depths of the soil profiles in irrigated lands of both lakes Abaya and Chamo.

Based on quantitative results (chemical and physical compositions), soils under Lake Abaya is in ranges of non-Saline non- sodic (Normal) to saline-sodic. From sampled soils across profile and spots $(17.5 \%$ saline sodic, $47.05 \%$ non-saline non-sodic and $35.29 \%$ of samples 
river there is also variability of soil compositions across the profiles and sampling spots, this lead to quality variable. The soil status under irrigated lands of Lake Chamo ranged from sodic (in Eligo) to saline sodic (in Shelle mella).

Based on water quality analysis of $\mathrm{P}^{\mathrm{H}}, \mathrm{SAR}, \mathrm{EC}$ and $\mathrm{RSC}$ the result revealed that water quality of lake Abaya is hazardous(highly saline class(C3) and very high sodicity class (S4). The results revealed that water is not suitable for irrigation purpose and it needs reclamations for sustainable soil and land management. According to the result of Lake Chamo the quality of water is classified as high salinity hazard (C3) and very sodicity hazard (S4) while the status of Sille river indicated that water is medium (S1) in salinity hazard. Based on salinity and sodicity hazard classification of USBR staff 1954 the water of lake Abaya and Chamo lake considered as unsuitable for irrigation purpose while Sille river is safe(suitable for irrigation).

The current study underscores the need for the scientific reclamation program of salt affected soils and waters for increasing the biological productivity of these problematic soils and water. In line with this, a due emphasis be given for frequent monitoring of irrigation waters, selection of suitable salt resistant varieties of crops, removing of excess salts by leaching, adopting judicious means of irrigation and fertilizer application together with the addition of organic manures and fallowing lands with the raclaimative grasses; for sustainable and productive utilization of land and water resources under irrigated lands lake Abaya and Chamo.

\section{REFERENCES}

Abejehu G. 1993. Assessment of salinity and sodicity status of soils of Matahara Sugar Estate. MSc Thesis, AUA, Alemaya, P 112.

Alamirew T.2002. Spatial and temporal variability of Awash River water salinity and the contribution of soil salinization in the Awash Valley of Ethiopia. Doctoral Dissertation, University of Natural Resources and Applied Life Sciences, Vienna, P 208 and Drainage Paper 29, Rev. 1, FAO, Rome.

Aisha Akram, Shagufta Shaheen, Sobia Naseer, Muhammad Ashraf and Nudrat,2013. Salt stress affects water relations, photosynthesis, and oxidative defence mechanisms in Solanum melongena L. Journal of Plant Interactions. https://doi.org/10.1080/17429145.2012.718376Brady NC, Weil, RR.2002. The nature and properties of soils. 10th ed. 
Bremner JM, Mulvaney CJ.1982. Nitrogen-total. In: AL. Page RH Miller and DR Keeney (eds.) Methods of Soil Analysis. Part II. Chemical and microbiological properties. Agronomy American Society of Agronomy Inc. Madison, Wisconsin. pp. 595-624.

Food and Agriculture Organization (FAO) 2002. Procedures for soil analysis. Six editions. Compiled and edited by Van Reeuwijk LP. International Soil Reference and Information Center (ISRIC), the Netherlands.119 http://www.isric.org/sites/default/files/ISRIC_TechPap09.pdf (Accessed date, 20 January, 2020)

Food and Agriculture Organization (FAO) 2006. Guidelines for Soil Description, fourth edition. Rome, Italy: FAO. P: 109.

Heluf G/K.1985. Investigation on salt affected soils and irrigation water quality in Melka Sedi-Amibara Plain, Rift Valley Zone of Ethiopia. MSc Thesis presented to the School of graduate Studies of Addis Ababa University 131p.

Horneck DA, Ellsworth JW, Hopkins BG, Sullivan DM, Stevens RG .2007. "Managing salt affected soils for crop production." Oregon State University.

Olsen SR, Cole CV, Watanabe FS, Dean LA.1954. Estimation of available Phosphorus in soil by extraction with sodium bicarbonate. USDA Circular 939:15-19.

Park JBK, Craggs RJ, Shilton AN.2011. Waste water treatment high rate algal ponds for biofuel production. J. Biores. Tech. 102:35-42 Prentice Hall.

Seid M, Genanew T.2013. Evaluation of soil and water salinity for irrigation in North-eastern Ethiopia: Case study of Fursa small scale irrigation system in Awash River Basin. Afr. J. Environ. Sci. Technol. 7(5):167-174.

US Salinity Laboratory Staff 1954. Diagnosis and improvement of saline and alkali soils. USDA Agri. Handbook. No. 60:160.

Van Reeuwijk L.1993. Procedures for soil analysis. 4th ed. International Soil Reference and Information Center, The Netherlands. Technical Paper No.1

Walkley A, Black CA.1934. An examination of method for determining soil organic matter and proposed modification of the proposed modification of the chromic acid titration method. Soil Sci. 37:29-38.

M. AKRAM1*, M. Y. ASHRAF, RASHID AHMAD , M. RAFIQ3 , I. AHMAD and JAVED IQBAL 2010. Allometry and yield components of maize (zea mays 1.) Hybrids to various potassium levels under saline conditions, Arch. Biol. Sci., belgrade, 62 (4), 1053-1061, 2010. 
278 Hodri, and P. Thomas 2011. Abstracts and extended abstracts submitted to the Global Forum on Salinization and Climate Change (GFSCC2010), Valencia, 25-29 October, 2010.

280 Mulat Asmamaw, Ashenafi Haile and Gezai Abera 2018. Characterization and classification 281 of salt affected soils and irrigation water in Tendaho sugarcane production farm, North282 Eastern Rift Valley of Ethiopia. African journal of Agricultural Research vol.13 (9), pp. 403283 411, March 2018 
Figures

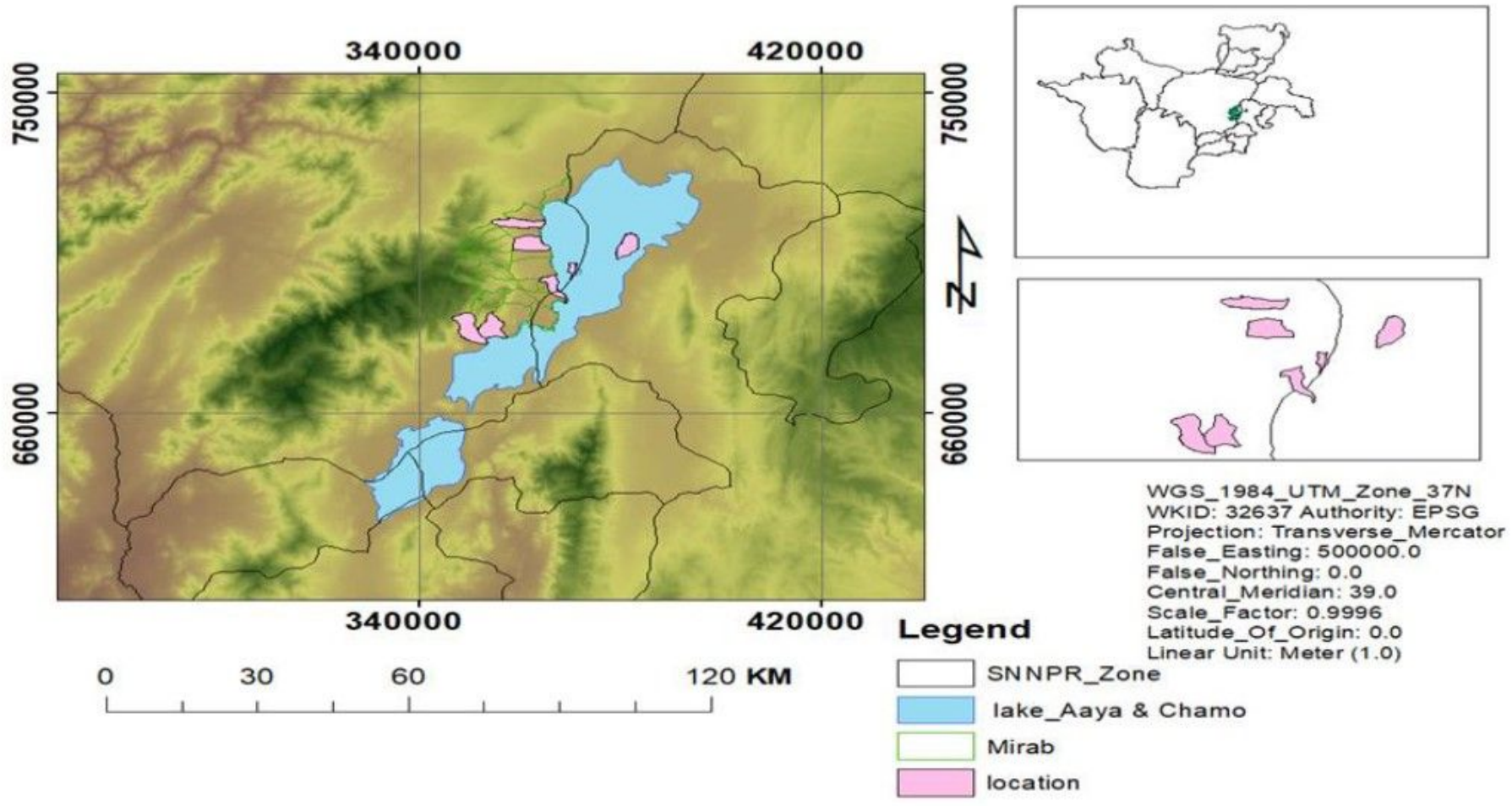

Figure 1

study area map

\section{Image not available with this version}

Figure 2

This image is not available with this version. 

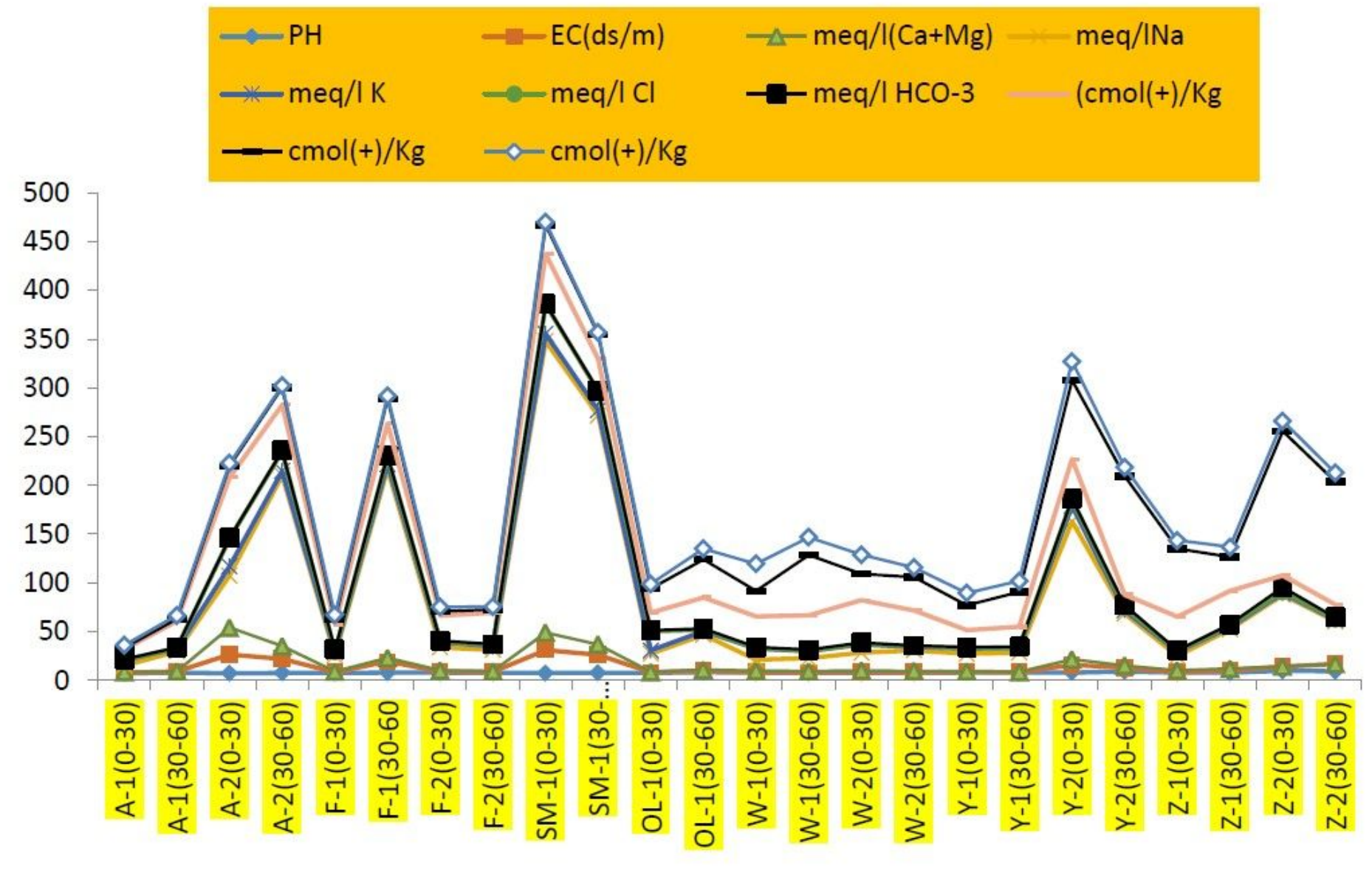

Figure 3

The soil chemical properties under Lake Abaya and Chamo 


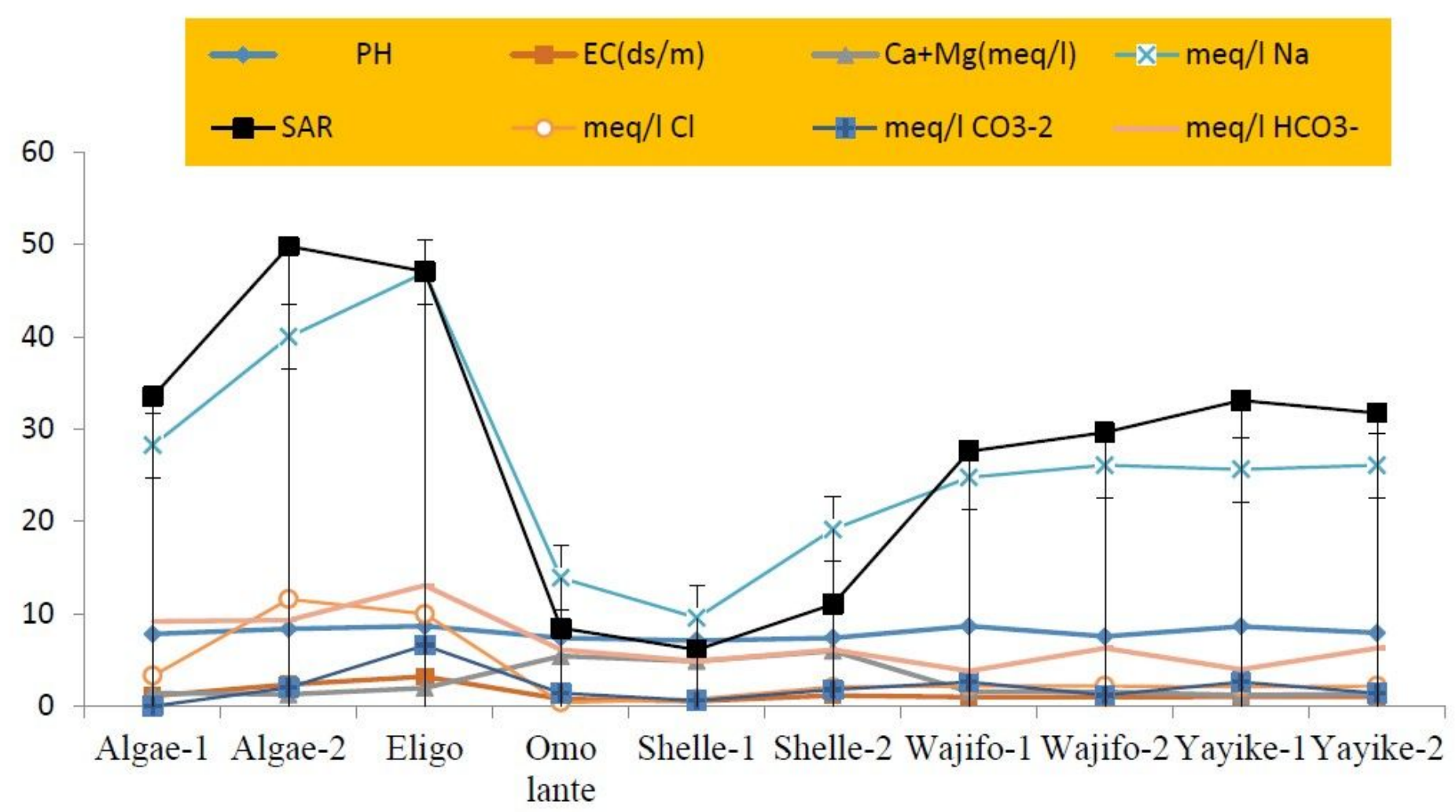

Figure 4

Chemical properties of water under Lake Abaya Chamo basin

\section{Supplementary Files}

This is a list of supplementary files associated with this preprint. Click to download.

- Table.pdf 